\title{
Reconstructing the secular evolution of boron isotope composition of seawater from evaporites
}

\author{
DR. HANA JURIKOVA ${ }^{1}$, JAMES W. B. RAE ${ }^{1}$, FERNANDO \\ GÁZQUEZ $^{2}$, ESZTER SENDULA ${ }^{3,4}$, ROBERT BODNAR ${ }^{3}$, \\ MEBRAHTU WELDEGHEBRIEL ${ }^{5}$ AND TIM \\ LOWENSTEIN $^{5}$ \\ ${ }^{1}$ University of St Andrews \\ ${ }^{2}$ University of Almería \\ ${ }^{3}$ Virginia Tech \\ ${ }^{4}$ University of Pécs \\ ${ }^{5}$ State University of New York \\ Presenting Author: jwbr@st-andrews.ac.uk
}

The ocean boron isotope composition is homogeneous, but varies over its residence time on time scales of approximately 10 million years. To date, however, the secular evolution of the oceanic boron isotope budget has been difficult to constrain. The lack of knowledge on past boron isotope composition of seawater $\left(\delta^{11} \mathrm{~B}_{\mathrm{sw}}\right)$ not only limits our understanding of global boron biogeochemical cycling through time, but poses the major uncertainty to reliable boron-based $\mathrm{pH}$ and $\mathrm{pCO}_{2}$ reconstructions from Earth's geologic past. Evaporites, and halites in particular, present a highly appealing archive for reconstructing $\delta^{11} \mathrm{~B}_{\mathrm{sw}}$ given their direct origin from seawater, however, the interpretation of their boron isotope signatures is not straightforward due to the possibility of fractionation during evaporation and crystallisation [1]. Here we present boron isotope evolution during evaporite formation from laboratory experiments and natural modern settings. These data enable us to place constraints on boron fractionation in ancient evaporites, offering new insights into $\delta^{11} \mathrm{~B}_{\mathrm{sw}}$ during some of the key periods of the Phanerozoic.

[1] Paris G., Gaillardet J., and Louvat P. (2010), Geology 38, 1035-1038, https://doi.org/10.1130/G31321.1. 